\title{
EFFECTIVENESS OF THE COMBINED USE OF ROBOTIC KINESIOTHERAPY AND BOTULINUM THERAPY IN THE COMPLEX REHABILITATION OF CHILDREN WITH CEREBRAL PALSY
}

\author{
BALGAYEVA MAIRA ${ }^{1 *}$, BULEKBAYEVA SHOLPAN ${ }^{2}$
}

${ }^{1}$ Department of Neurology, Astana Medical University, Astana, Kazakhstan. ${ }^{2}$ Department of Neurology, The National Children's Rehabilitation Center, The Corporate Fund University Medical Center, Astana, Kazakhstan. Email: maira.balgayeva@gmail.com

Received: 09 April 2018, Revised and Accepted: 01 June 2018

\section{ABSTRACT}

Objective: The objective of this study is to evaluate the effectiveness of combined use of robotic kinesiotherapy and botulinum therapy in the complex rehabilitation of children with spastic diplegia.

Methods: In the research, 162 children were participated in the age from 4 to 6 years with spastic diplegia. The main group was carried out using robotic kinesiotherapy with the help of the Lokomat complex and intramuscular injection of botulinum toxin type A (BtA), as a part of complex rehabilitation. Children from the control group received rehabilitative treatment with traditional methods.

Results: During the comparative study of groups, higher results were obtained in the main group, where average according to Gross Motor Function Measure 88 increased from 69.99 to 76.41 with a difference of 6.42 points $(\mathrm{p}=0.0001)$. In the control group, this indicator increased from 67.01 to 69.41 with a difference of 2.4 points. In the main group, a moderate coupling was noticed between overall motor activity improvement and muscle tone improvement $(\mathrm{rs}=0.411, \mathrm{p}=0.001)$. Herewith, the correlation was pronounced more with children of the III level in Gross Motor Function Classification System $\left(r_{s}=0.483, p=0.002\right)$ in comparison with the II development level $\left(r_{s}=0.304, p=0.042\right)$.

Conclusion: Research results indicated that the children with spastic diplegia have significant improvement in motor characteristics when the combined applying of robotic walking and botulinum therapy compared with conventional therapy. In our opinion, the data obtained allow to recommend this method as one of the perspective methods of rehabilitation treatment for children with spastic forms of cerebral palsy.

Keywords: Cerebral palsy, Multidisciplinary rehabilitation, Robotic walking, Botulinum therapy.

(c) 2018 The Authors. Published by Innovare Academic Sciences Pvt Ltd. This is an open access article under the CC BY license (http://creativecommons. org/licenses/by/4. 0/) DOI: http://dx.doi.org/10.22159/ajpcr.2018.v11i9.26541

\section{INTRODUCTION}

Development of modern technologies in the complex rehabilitation of patients with disabilities is one of the most important objects in the health-care system. In particular, this refers to the rehabilitation treatment of children with cerebral palsy (CP) since this disease is the most common cause of disability in childhood.

According to epidemiological survey, the total prevalence of $\mathrm{CP}$ is 2.1 cases per 1000 live-born children and remains stable over the past decade [1]. It is important to emphasize that the CP prevalence data in the Republic of Kazakhstan exceed the average world statistical data [2].

As of today, effective methods for the rehabilitation of children with $\mathrm{CP}$ are not enough, which requires finding new approaches to disordered function recovery. The key points of modern neurorehabilitation are patients' active involvement in the rehabilitation process and achievement of a high level of independence in daily activities [3]. Consequently, the introduction of high-tech rehabilitation complexes became the priority direction of motor rehabilitation of children with CP [4]. One of the latest achievements in this regard is the introduction of a complex of robotic kinesiotherapy "Lokomat," which is used in patients with motor disorders of cerebral genesis.

According to the literature data, there is strong proof of motor function improvement after the application of robotic kinesiotherapy for adult patients with spinal cord trauma and also in ischemic stroke recovery period $[5,6]$. At the same time, according to a number of studies, using robotic walking does not always exceed the results of traditional kinesiotherapy methods [7].
Today, there is not enough research-based evidence of robotic technologies using in the child's neurorehabilitation. Data of the robotic kinesiotherapy effectiveness in the comprehensive rehabilitation of children with CP are varying and contradictory [8]. A number of studies have shown the connection between exercises of robotic kinesiotherapy and improvements of the gross motor function, speed and endurance of walk, kinematics of the lower limbs in varying degrees, and social activity improvement [9-12]. At the same time, a study by Drużbicki et al. devoted to a comparative study of the robotic kinesiotherapy effect and conventional kinesiotherapy on motor skills improving has not identified statistically significant changes of gait parameters in the both groups of children with spastic diplegia [13]. Due to a number of limitations, the research was interpreted by authors as the preliminary and the requiring further study. According to Peri et al. data, the combined use of robotic kinesiotherapy and traditional physical therapy does not exceed the results of their isolated using regardless by the therapy course duration [14].

However, training of robotic walking in neurorehabilitation today is recommended as an additional treatment tool but not as a traditional kinesiotherapy substitute $[15,16]$. Taking into account dissimilarity of research results in this direction, there is a need for further clinical studies that would evaluate the effectiveness of current principles of their use for children with CP to find new approaches for effective rehabilitation.

An integral part of the rehabilitation therapy complex for children with $\mathrm{CP}$ is the normalization of muscle tone. Botulinum toxin type A (BtA), which used for this purpose, has proved itself as a safe and effective method of treatment, and it is also widely used not only in neurology 
but also in other areas, in particular in dermatology [17] and dental practice $[18,19]$.

A number of studies are made to emphasize the importance of combined physical therapy and BtA treatment [20]. However, in the available literature, there are no data on the evaluation of the effectiveness of robotic kinesiotherapy use with the help of the Lokomat complex on the background of medicamentous therapy of muscular spasticity in CP cases, which predetermined the relevance of the study. In our study, a comparative assessment of the clinical effectiveness of the combined use of robotic kinesiotherapy and botulinum therapy in the complex rehabilitation of children with spastic diplegia was conducted for the first time.

\section{METHODS}

The research was performed at the National Children's Rehabilitation Center in Astana city. The study was endorsed by the Local Ethics Committee of the Astana Medical University. In research, 162 children were participated in age from 4 to 6 years with CP, spastic diplegia, which received a comprehensive multidisciplinary rehabilitation. 82 children were included in the main group, whereas a part of complex rehabilitation was additionally carried out robotic kinesiotherapy using the Lokomat complex and intramuscular injection of BtA. The control group consisted of 80 children who received rehabilitative treatment with traditional methods.

The inclusion criteria were CP diagnosis, spastic diplegia, the patients' age should be 4 years and older, and the motor development level according to Gross Motor Function Classification System (GMFCS) II and III.

The exclusion criteria were severe concomitant somatic pathology, uncontrolled epileptic seizure, orthopedic surgery, hip joint instability, and concomitant diseases with clinical signs of motor damage (congenital genetic syndromes and chromosomal diseases). BTA injection exclusion criteria were acute inflammatory conditions, hyperthermia, pathological characteristics of the general analysis of blood and urine, and persistent contracture.

To evaluate the effectiveness of therapy, the following were used: the Gross Motor Function Measure (GMFM 88), the Modified Ashworth Scale for Grading Spasticity, and self-service scale. According to GMFCS, children are divided into two subgroups: II and III levels.

\section{Participants}

Distribution of patients by age, gender, and motor development level according to GMFCS is given in Table 1.
Observed children's average age in the main group was $4.84 \pm 0.56$ years and in the control group - $4.78 \pm 0.61$ years. Most of the children in both survey groups were boys $58.54 \%$ in the main group and $56.25 \%$ in the control group). There were no significant differences in the age and gender characteristics between the survey groups. Furthermore, there were no statistically significant differences between groups in terms of motor deficit ( $p=0.436$ ). As the results showed, the compared groups were commensurate with severity of pathology, and significant differences in the initial representation of abnormalities of the studied parameters in the main group and in the control group were not determined before rehabilitation course $(p>0.05)$.

\section{Procedures}

Duration of the rehabilitation course was 24 days. Rehabilitation course included physiotherapeutic procedures, corrective lessons with psychologist, logopedist, music therapist, ergotherapist, hydrokinesiotherapy, physical therapy, and orthotics. Additionally, in the main group were carried out robotic walking on the Lokomat complex and BtA injection (Dysport). Robotic kinesiotherapy course averaged $10.07 \pm 0.82$ sessions (range 8-12), duration of each session was $30.17 \pm 0.79 \mathrm{~min}$ (range 30.0-34.4), the average walk for the therapy session was $547.35 \pm 98.57 \mathrm{~m}$ (range 372.64-758.75), and the total distance traveled is $5488.18 \pm 950.92 \mathrm{~m}$ (range 3970-6822). BtA injection was given intramuscularly as a single dose. The dose depended on the body weight, size of the target muscle, severity, and prevalence of muscle spasticity. The average administered dose of the medication was $342.45 \pm 63.78$ units (range 230-460).

\section{Statistical analysis}

Statistical analysis of this study results was carried using IBM SPSS Statistics Professional 21.0. To describe the distribution of data, we used separate descriptive statistics. The value of the rehabilitation results was measured using the Wilcoxon test. These comparisons are related to both groups: The main group and the control group. The value of the differences between the two groups was estimated using a nonparametric Mann-Whitney test. To determine the degree of dependence between the studied parameters, we used the correlation analysis with the Spearman coefficient $\left(\mathrm{r}_{\mathrm{s}}\right)$ counting. Estimated statistically significant level was $p \leq 0.05$. During the describing of qualitative and order characteristics, the absolute and relative frequencies of the trait in the group were analyzed, and the result was expressed as a percentage of the total number of values.

\section{RESULTS}

Data analysis of general motor development after obtaining of the rehabilitation program course indicates that both groups

Table 1: Characteristics of survey groups

\begin{tabular}{llll}
\hline Characteristics & Main group & Control group & p \\
\hline Age, years, Mean \pm SD & $4.84 \pm 0.56$ & $4.78 \pm 0.61$ & 0.570 \\
Gender: Males/ & $48 / 34(58.54 / 41.46)$ & $45 / 35(56.25 / 43.75)$ & 0.772 \\
females, n (\%) & $45(54.88)$ & $39(48.75)$ & 0.436 \\
GMFCS II, n (\%) & $37(45.12)$ & $41(51.25)$ & 0.156 \\
GMFCS III, $\mathrm{n}(\%)$ & $2.84(0.72)$ & $2.66(0.50)$ & \\
MAS, Mean \pm SD & & & \\
\hline
\end{tabular}

Main group n=82, Control group n=80, GMFCS: Gross Motor Function Classification System, MAS: Modified Ashworth Scale For Grading Spasticity, SD: Standard deviation

Table 2: The dynamics of general motor development indicators by GMFM-88

\begin{tabular}{|c|c|c|c|c|c|c|c|c|c|}
\hline \multirow[t]{3}{*}{ Levels } & \multicolumn{2}{|l|}{ Before } & \multirow[t]{3}{*}{$\mathbf{p}$} & \multicolumn{2}{|l|}{ After } & \multirow[t]{3}{*}{ p } & \multicolumn{2}{|l|}{ Difference } & \multirow[t]{3}{*}{$\mathbf{p}$} \\
\hline & Main group & Control group & & Main group & Control group & & Main group & Control group & \\
\hline & Mean \pm SD & & & Mean \pm SD & & & Mean \pm SD & & \\
\hline GMFCS II & $81.95 \pm 5.68$ & $79.68 \pm 7.20$ & 0.183 & $87.19 \pm 5.55$ & $82.07 \pm 7.48$ & 0.002 & $5.24 \pm 2.41$ & $2.39 \pm 1.26$ & 0.0001 \\
\hline GMFCS III & $55.44 \pm 7.40$ & $54.95 \pm 7.24$ & 0.589 & $63.31 \pm 7.48$ & $57.38 \pm 7.38$ & 0.001 & $7.86 \pm 4.01$ & $2.42 \pm 1.78$ & 0.0001 \\
\hline GMFCS II \& III & $69.99 \pm 14.76$ & $67.01 \pm 14.35$ & 0.171 & $76.41 \pm 13.59$ & $69.41 \pm 14.45$ & 0.002 & $6.42 \pm 3.47$ & $2.40 \pm 1.54$ & 0.0001 \\
\hline
\end{tabular}

GMFCS: Gross Motor Function Classification System, SD - standard deviation; probability (p) was calculated using the Mann-Whitney U-test 
have a statistically significant increase of the motor development score, which indicates an improvement of the motor abilities of all surveyed children (Table 2). During the comparative study of groups, higher results were obtained in the main group, where average motor development index increased from 69.99 to 76.41 with a difference of 6.42 points $(\mathrm{p}=0.0001)$. In the control group, this indicator increased from 67.01 to 69.41 with a difference of 2.4 points. More significant progress was noted in the patients of the main group of the III development level according to GMFCS. Their motor development score increased from 55.44 to 63.31 with a difference of 7.86 points $(\mathrm{p}=0.0001)$, while in the control group, this indicator increased from 54.95 to 57.38 with a difference of 2.42 points.

In the main group, there was a significant decrease of the muscle spasticity level after the rehabilitation course, in comparison with the initial value (before the rehabilitation course $2.84 \pm 0.72$ and after the course of rehabilitation $-2.08 \pm 0.68$ ), the differences are significant $(p<0.0001)$. In the control group, there was also an improvement of the indicator values after the rehabilitation course, in comparison with the indices before the beginning of rehabilitation $(2.66 \pm 0.50$ and $2.58 \pm 0.52, p=0.034$ ), which were less pronounced. Heedless of the fact that the children in the control group did not receive medication for spasticity reducing, and conducted complex actions had a positive effect on the patients' muscle tone.

There was a significant mean power correlation relationship found between the improvement in overall motor activity and a decrease in spasticity of the main group as a whole $\left(r_{s}=0.411, p=0.001\right)$. Depending on GMFCS, correlation was more pronounced in children with the III development level $\left(r_{s}=0.483, p=0.002\right)$ and less pronounced for GMFCS II level $\left(r_{s}=0.304, p=0.042\right)$. In the control group, the binding force was defined as weak $\left(r_{s}=0.246, p=0.028\right)$, and concurrently depending on GMFCS level, there is no difference (GMFCS III - $r_{s}=0.276, p=0.089$, and GMFCS II $-r_{s}=0.211, p=0.185$ ). On the basis of received data, we tend to believe that the improvement of muscle tone positively affects motor skills formation, especially in children with more severe lesions.

Table 3: Dynamics of motor activity indices of the main group according to the Lokomat standard tests

\begin{tabular}{llll}
\hline Index & & \multicolumn{2}{l}{ Mean \pm SEM } \\
\cline { 3 - 4 } & & Before & After \\
\hline L-FORCE $(\mathrm{Nm})$ & $\mathrm{s}$ & $3.70 \pm 0.34$ & $6.67 \pm 0.43^{* * *}$ \\
& $\mathrm{~d}$ & $5.10 \pm 0.32$ & $9.98 \pm 0.63^{* * *}$ \\
$\mathrm{~L}-\mathrm{STIFF}\left(\mathrm{Nm} /{ }^{\circ}\right)$ & $\mathrm{s}$ & $2.27 \pm 0.06$ & $1.55 \pm 0.03^{* * *}$ \\
& $\mathrm{~d}$ & $2.36 \pm 0.06$ & $1.82 \pm 0.03^{* * *}$ \\
$\mathrm{~L}-\mathrm{ROM}\left({ }^{\circ}\right)$ & $\mathrm{s}$ & $115.73 \pm 1.93$ & $128.97 \pm 1.60^{* * *}$ \\
& $\mathrm{~d}$ & $101.09 \pm 3.24$ & $124.03 \pm 2.37^{* * *}$ \\
\hline
\end{tabular}

Data on the motor activity assessment of the main group using standard tests included in the software of the Lokomat complex are presented in Table 3. According to the presented data, there is a clear positive dynamics of the lower limb muscle strength improvement, reducing of the spasticity of the lower limb muscles and increasing of motions of the lower limbs ranges. However, the informational content is limited because these tests were not conducted in the control group.

We used the self-service scale for the objectification of the surveyed children's ability to perform various types of domestic skills. Identification of self-service disturbance was carried out in accordance with the following criteria: Complete dependence, moderate dependence, and light dependence. It was found that children of both groups in terms of self-service and household adaptation are retarded the age norm.

Self-care improvement with the transition to an easier group at the end of the therapy was observed in 12 patients in the main group $(p=0.038)$, which significantly exceeded the results of the control group, where improvement was noted in 4 patients (Table 4). At the end of the rehabilitation course, $69.51 \%$ of the patients in the main group experienced moderate dependence, $20.73 \%$ had light dependence, and the complete dependence was maintained in $9.76 \%$ of patients. In the control group, $55.00 \%$ of patients experienced a moderate dependence, and a complete dependence of $21.25 \%$. At the same time, the number of patients with light dependence in self-care after the rehabilitation course was $23.75 \%$

Average indicator analysis revealed that, by the end of the rehabilitation course in both groups, there were significant changes in the formation of self-service skills (Table 5). In addition to the above, the most significant changes were noted with the children referred to the group of moderate and total dependence according to the baseline data $(\mathrm{p}<0.0001)$. Intergroup comparison revealed that the children experiencing complete dependence showed better results in the main group. Children with moderate and light dependence had no significant differences.

\section{DISCUSSION}

In our research, we studied the changes in motor and sociodaily activity in the combined use of robotic kinesiotherapy and botulinum therapy in complex rehabilitation of children with spastic diplegia. The results showed a clinically significant improvement in motor activity according to GMFM 88 in the patients of the main group, which indicates the effectiveness of the use of robotic kinesiotherapy against the background of reduction in muscle spasticity. According to Wang and Yang data, who studied the correlation between clinical improvement and GMFM score results, change in the GMFM 88 scale by a mean of 3.99 may be interpreted as a clinically significant improvement [21]. Furthermore, the improvement of indicators in motor activity was

Table 4: Comparative data on the impact of rehabilitation course on the level of self-care

\begin{tabular}{|c|c|c|c|c|c|c|}
\hline \multirow[t]{2}{*}{ Groups } & \multicolumn{2}{|c|}{ Complete dependence } & \multicolumn{2}{|c|}{ Moderate dependence } & \multicolumn{2}{|c|}{ Light dependence } \\
\hline & $\mathbf{n}$ & $\mathrm{P} \pm \mathrm{m} \%$ & $\mathbf{n}$ & $\mathrm{P} \pm \mathrm{m} \%$ & $\mathbf{n}$ & $\mathrm{P} \pm \mathbf{m} \%$ \\
\hline \multicolumn{7}{|l|}{ Main group: } \\
\hline Before & 20 & $24.39 \pm 4.74$ & 48 & $58.54 \pm 5.44$ & 14 & $17.07 \pm 4.16$ \\
\hline After & 8 & $9.76 \pm 3.28$ & 57 & $69.51 \pm 5.08$ & 17 & $20.73 \pm 4.48$ \\
\hline Improvement in the main group & 12 & $14.63 \pm 3.90^{*}$ & 9 & $10.98 \pm 3.45^{*}$ & 3 & $3.66 \pm 2.07$ \\
\hline \multicolumn{7}{|l|}{ Control group: } \\
\hline Before & 21 & $26.25 \pm 4.92$ & 42 & $52.50 \pm 5.58$ & 17 & $21.25 \pm 4.57$ \\
\hline After & 17 & $21.25 \pm 4.57$ & 44 & $55.00 \pm 5.56$ & 19 & $23.75 \pm 4.76$ \\
\hline Improvement in the control group & 4 & $5.00 \pm 2.44$ & 2 & $2.50 \pm 1.75$ & 2 & $2.50 \pm 1.75$ \\
\hline
\end{tabular}

P: The proportion of units that have this symptom in the group, $\mathrm{m} \%$ : The average error of the relative indicator, *statistically significant differences between groups, $\mathrm{P}<0.05$ 
Table 5: The dynamics of self-service indicators by the self-service scale

\begin{tabular}{|c|c|c|c|c|c|c|c|c|}
\hline \multirow[t]{2}{*}{ Level } & \multicolumn{2}{|c|}{ Main group Mean \pm SD } & \multicolumn{6}{|c|}{ Control group Mean \pm SD } \\
\hline & Before & After & Before & After & p1 & p2 & p3 & p4 \\
\hline Complete dependence & $50.75 \pm 9.35$ & $65.00 \pm 7.07$ & $54.04 \pm 4.64$ & $59.04 \pm 5.83$ & $0.410 \alpha$ & $0.006 \alpha$ & $0.0001 \gamma$ & $0.0001 \gamma$ \\
\hline Moderate dependence & $91.45 \pm 17.13$ & $102.60 \pm 18.96$ & $90.83 \pm 19.59$ & $95.95 \pm 19.88$ & $0.788 \alpha$ & $0.132 \alpha$ & $0.0001 \gamma$ & $0.0001 \gamma$ \\
\hline Light dependence & $138.92 \pm 10.41$ & $148.21 \pm 11.70$ & $141.47 \pm 14.76$ & $144.41 \pm 16.28$ & $0.886 \alpha$ & $0.184 \alpha$ & $0.001 \gamma$ & $0.008 \gamma$ \\
\hline All & $89.63 \pm 31.67$ & $101.21 \pm 30.80$ & $91.93 \pm 34.04$ & $96.56 \pm 33.68$ & $0.856 \alpha$ & $0.257 \alpha$ & $0.0001 \gamma$ & $0.0001 \gamma$ \\
\hline
\end{tabular}

p1: Difference between main group and control group before therapy, p2: Difference between main group and control group after therapy, p3: Difference in main group before and after therapy, p4: Difference in control group before and after therapy, $\alpha$ : Mann-Whitney U-test, $\gamma$ : Wilcoxon signed-rank test

corresponding to the patient's and their parents' perceptions, which indicated an increase in muscle strength and endurance during exercise. It should be noted that more significant changes in motor development were observed in children with the III development level, especially in children of the main group. Similar results were obtained in other studies when children with $\mathrm{CP}$ with more severe motor development disorders achieved better results $[22,23]$.

Self-service improvement in our research is an indirect evidence of the effectiveness of combined therapy with the use of robotic walking and botulinum therapy for children with CP. Motor skill improvement reflects not only on the ability to move but also on patients' daily and social activity [24]. Although the used scale is not specific for assessing of the robotic walking effectiveness, it can indicate an improvement of motor skills in general. More accurate test for assessing walking skills is the Functional Independence Measure for Children (WeeFIM) scale. Literature available data on the daily activity evaluation on the WeeFim scale after the use of robotic walking indicate a significant improvement in mobility in children with CP. With that, the children with more serious disorders showed better results than the children with moderate impairment of motor development [22]. These data are consistent with the information obtained in our study, where children with more serious developmental disorders showed better results both on the GMFM 88 scale and the self-service scale. However, according to Borggraefe et al., children with III-IV levels of GMFCS development demonstrated a lower potential, which contradicts our data [11]. Perhaps, this contradiction is due to the limited number of samples in the research.

We have not found data on the robotic walking use in combination with botulinum therapy for children with $\mathrm{CP}$ in the available literature. Although BtA injection can be useful in therapy with Lokomat complex, as reducing spasticity of the muscles ensures painlessness of training on the treadmill. Furthermore, a muscle tone decrease prevents the activation of the controller and stops the device at the beginning of therapy [16]. There were no difficulties during the exercise at Lokomat complex. We have not observed any unwanted side effects of botulinum therapy use.

\section{CONCLUSION}

Thus, research results indicated that the children with spastic diplegia have significant improvement in motor characteristics when the combined applying of robotic walking and botulinum therapy compared with conventional therapy. There was also a significant improvement in self-service skills, which is the main goal of rehabilitation of children with disabilities. The lack of data on the evaluation of the effectiveness of robotic walking use against the background of reducing spasticity does not allow us to compare our results with other studies. However, in our opinion, the data obtained allow to recommend this method as one of the perspective methods of rehabilitation treatment of the children with spastic forms of CP.

\section{ACKNOWLEDGMENT}

We want to thank all patients for their participation in this study. And also, we are very grateful to all the employees of the National Children's Rehabilitation Center for practical assistance.

\section{AUTHOR'S CONTRIBUTIONS}

Both authors have made substantial contributions to the work reported in the manuscript. The first author: Conception and designing of the study, acquisition of data, analysis and interpretation of data, and drafting the manuscript. Second author: Analysis and interpretation of data, revising the manuscript critically for important intellectual content, and final approval of the study to be published.

\section{CONFLICTS OF INTEREST}

The authors confirm that this article content has no conflicts of interest.

\section{REFERENCES}

1. Oskoui M, Coutinho F, Dykeman J, Jetté N, Pringsheim T. An update on the prevalence of cerebral palsy: A systematic review and metaanalysis. Dev Med Child Neurol 2013;55:509-19.

2. Health of the population of the Republic of Kazakhstan and the activities of health organizations: Statistical compilations for 20052016. Available from: http://www.rcrz.kz/index.php/ru/?option=com content $\&$ view $=$ article $\& i d=973$.

3. Bulekbayeva S, Daribayev Z, Ospanova S, Vento S. Cerebral palsy: A multidisciplinary, integrated approach is essential. Lancet Glob Health 2017;5:e401.

4. Bulekbayeva S, Abdrakhmanova A, Ospanova S, Rizvanova A, Shalbarbaeva G, Kharina YU. Innovative technologies in the rehabilitation of children with neurological pathology in the republican children's rehabilitation center. Vestnik AGIUV 2011;43-4.

5. Nam KY, Kim HJ, Kwon BS, Park J-W, Lee HJ, Yoo A. Robot-assisted gait training (Lokomat) improves walking function and activity in people with spinal cord injury: A systematic review. J Neuroeng Rehabil 2017;14:24.

6. Bruni MF, Melegari C, De Cola MC, Bramanti A, Bramanti P, Calabrò RS. What does best evidence tell us about robotic gait rehabilitation in stroke patients: A systematic review and meta-analysis. J Clin Neurosci 2018;48:11-7.

7. Hidler J, Nichols D, Pelliccio M, Brady K. Campbell DD, Kahn JH, et al. Multicentre randomized clinical trial evaluating the effectiveness of the Lokomat in subacute stroke. Neurorehabil Neural Repair 2009;23:5-13.

8. Castelli E. Robotic movement therapy in cerebral palsy. Dev Med Child Neurol 2011;53:481.

9. Drużbicki M, Rusek W, Szczepanik M, Dudek J, Snela S. Assessment of the impact of orthotic gait training on balance in children with cerebral palsy. Acta Bioeng Biomech 2010;12:53-8.

10. Wallard L, Dietrich G, Kerlirzin Y, Bredin J. Effect of robotic-assisted gait rehabilitation on dynamic equilibrium control in the gait of children with cerebral palsy. Gait Posture 2018;60:55-60.

11. Borggraefe I, Schaefer JS, Klaiber M, Dabrowski E, AmmannReiffer C, Knecht B, et al. Robotic-assisted treadmill therapy improves walking and standing performance in children and adolescents with cerebral palsy. Eur J Paediatr Neurol 2010;14:496-502.

12. Schroeder AS, Homburg M, Warken B, Auffermann H, Koerte I, Berweck S, et al. Prospective controlled cohort study to evaluate changes of function, activity and participation in patients with bilateral spastic cerebral palsy after Robot-enhanced repetitive treadmill therapy. Eur J Paediatr Neurol 2014;18:502-10.

13. Drużbicki M, Rusek W, Snela S, Dudek J, Szczepanik M, Zak E, et al. Functional effects of robotic-assisted locomotor treadmill therapy in children with cerebral palsy. J Rehabil Med 2013;45:358-63.

14. Peri E, Turconi AC, Biffi E, Maghini C, Panzeri D, Morganti R, et al. Effects of dose and duration of robot-assisted gait training on walking 
ability of children affected by cerebral palsy. Technol Health Care 2017;25:671-81.

15. Calabrò RS, Cacciola A, Bertè F, Manuli A, Leo A, Bramanti A, et al. Robotic gait rehabilitation and substitution devices in neurological disorders: Where are we now? Neurol Sci 2016;37:503-14.

16. Aurich-Schuler A, Warken B, Graser JV, Ulrich T, Borggraefe I, Heinen $\mathrm{F}$, et al. Practical recommendations for robot-assisted treadmill therapy (Lokomat) in children with cerebral palsy: Indications, goal setting, and clinical implementation within the WHO-ICF framework. Neuropediatrics 2015;46:248-60.

17. Alodeani EA. Botulinum toxin type A: An effective, safe and minimally invasive treatment option of axillary and palmar hyperhidrosis. Int $\mathrm{J}$ Pharm Pharm Sci 2016;8:237-40.

18. Vidya VS, Felicita AS. Efficacy of pharmacological agents in the treatment of temporomandibular joint disorder: A systematic review. Int J Pharm Pharm Sci 2015;7:54-8.

19. Kumar S. The emerging role of botulinum toxin in the treatment of orofacial disorders: Literature update. Asian J Pharm Clin Res
2017;10:21-9.

20. Fonseca PR Jr. Franco de Moura RC, Galli M, Santos Oliveira C. Effect of physiotherapeutic intervention on the gait after the application of botulinum toxin in children with cerebral palsy: Systematic review. Eur J Phys Rehabil Med 2017; doi: 10.23736/S1973-9087.

21. Wang HY, Yang YH. Evaluating the responsiveness of 2 versions of the gross motor function measure for children with cerebral palsy. Arch Phys Med Rehabil 2006;87:51-6.

22. Van Hedel HJ, Meyer-Heim A, Rüsch-Bohtz C. Robot-assisted gait training might be beneficial for more severely affected children with cerebral palsy. Dev Neurorehabil 2016;19:410-5

23. Willoughby KL, Dodd KJ, Shields N. A systematic review of the effectiveness of treadmill training for children with cerebral palsy. Disabil Rehabil 2009;31:1971-9.

24. Lee BH. Relationship between gross motor function and the function, activity and participation components of the international classification of functioning in children with spastic cerebral palsy. J Phys Ther Sci 2017;29:1732-6. 